\title{
Usability Cost-Benefit Analysis for Information Technology Applications and Decision Making
}

\author{
Mikko Rajanen, Ph.D. \\ University of Oulu, Finland \\ Dr. Mikko Rajanen, University of Oulu (mikko.rajanen@oulu.fi)
}

\begin{abstract}
Usability is an important quality attribute for Information Technology (IT) applications. However, integrating usability design and evaluation as an integral part of the development processes in Information Technology development organizations is still a challenge. This chapter gives an overview on the usability cost-benefit analysis models and provides some example cases of the importance of usability. These models and cases can be used by usability professionals to motivate the organizational management to provide resources for usability work and to integrate usability work as part of the development process. The target audience for this chapter are professionals and researchers working in the field of IT, managers in IT development organizations, as well as managers in organizations acquiring and using IT.
\end{abstract}

Keywords: Usability, User Experience, Cost-Benefit Analysis, Cost-Justifying, Information Technology Applications, Usability Improvement, User-Centered Design, Usability Work

Mikko Rajanen is a post-doctoral researcher at INTERACT Research Unit, University of Oulu, Finland. He has a Ph.D. degree in Information Systems and over 20 years of experience in usability research and teaching. His research interests include usability cost-benefit analysis, usability in open source software development context, and usability in games and gamification. He has been involved in local usability community, organizing the World Usability Day and initiating the UKKOSS research project for bringing the usability methods, processes and practices into open source software development context. His goal is to make the world a better place one user interface at the time.

\section{INTRODUCTION}

Today, we use Information Technology applications, software, information systems and online services more than ever before. These applications, systems and services play a crucial role in the everyday and working life of individuals, organizations and the society at large, and they impact the lives of all people. Therefore, it is more important than ever to ask why these systems are often so difficult to use. To quote the founder of Macintosh project at Apple, Jef Raskin (2001): "As far as the customer is concerned, the interface is the product." This means that as far as the real users are concerned, all the innovative and creative technical solutions and functionalities of the system created by the development organizations have been designed and developed in vain if the users cannot easily use them. 
The mission of this chapter is to give a 1) comprehensive overview as well as 2) example cases of the importance of good usability and user experience (UX) for the development organizations, customer organizations and end users, as well as providing 3) practical tools for the management for making strategic business cases for better usability and UX, and introducing usability and UX activities into the development process. The target audience for this chapter are professionals and researchers working in the field of Information Technology, managers in IT development organizations, as well as managers in organizations acquiring and using IT. While the topic is important for the managers in development organizations and customer organizations, there are surprisingly few books or research articles on this topic, and even the newest practical guidebook, the "Cost-Justifying Usability" is now over 15 years old. The overview on usability and UX, as well as the example cases presented in these old books and articles are in great need of a complete update. In addition to providing a new and up to date overview on the importance of usability and UX, and giving modern example cases of usability benefits, this chapter will further expand the usability cost-benefit analysis into new contexts which are not currently presented in books or articles, namely games, gamification and open source software development. To achieve this mission, the author of the chapter will reflect on his own research on the topic from the last 15 years, as well as the experience and data that he has gathered during this research.

\section{BACKGROUND}

Usability is defined as one of the main quality attributes for Information Technology applications, software products, information systems and online services (Marghescu, 2009). There are many international standards and recognized definitions of usability and user-centered design, which all have different focuses (Marghescu, 2009) First international standard referring to the usability defined it as the capability of the product to be understood, learned, used by, and attractive to the user, when used under specified conditions (ISO 9126). The second international standard defining usability is the standard ISO 9241-11, where usability is defined as being the extent to which a product can be used by specified users to achieve specified goals with effectiveness, efficiency, and satisfaction in a specified context of use (ISO 9241). The third common usability definition is by Nielsen and Schneiderman, who define usability as consisting of five quality components: learnability, efficiency, memorability, errors, and satisfaction (Nielsen 1993, Schneiderman 1998). Usability can be achieved through a user-centered design process, usability activities (e.g., usability testing, paper prototyping, heuristic evaluation), and having an overall focus on usability issues through the entire development process (c.f. Rajanen et al. 2017, Rajanen \& Rajanen 2017). Furthermore, since the turn of the millennia, the concept of user experience (UX) has been introduced to take into account the emotions and attitudes of user about using a particular product, system or service (ISO 13407, Marghescu 2009).

Usability design and evaluation as a field has struggled since its beginning for legitimacy (Rajanen \& Iivari 2007). Furthermore, there is a wide diversity on the usability professionals' design and evaluation practices, as well as their conceptualization of usability and user experience (Rajanen et al. 2017). Fortunately, there has also been a lot of progress when it comes to making usability improvement activities an integral part of the development process. These days the development companies usually acknowledge the importance of usability and see it as important factor for their success. However, still too often the usability improvement activities are amongst the first to be sacrificed whenever the product needs to be on the market as soon as possible. Furthermore, there is still some traditional views amongst the development company management that see the usability improvement activities as just an additional and maybe even an optional task in software development projects. In the eyes of these managers, such an 'extra' task is always a potential risk for project deadlines and can be among the first to be cut from the project planning. Often these managers try to justify poor usability with the argument that the users can be trained and that sooner or later, these users will learn to overcome the usability problems in the system and adapt their workflow to the intricacies of the software. However, it is also possible that the users simply refuse to learn to use the system with poor usability, and that the functionality that has been implemented in the system with so much cost and effort 
is never used. Furthermore, poor usability, and hence a stressful work situation, is still a severe problem in computer-supported work, despite efforts to solve these issues. Stressful work situation due to poor usability of the Information Technology applications that need to be used in the day to day work has been identified as an important reason for high employee turnover. The most skilled and experienced employees can start searching for a better place for working, if they feel that their current work is hampered by these unsuitable and difficult to use information systems, tools and services. The less experienced employees may not be able to change their employer so easily, but their work satisfaction and efficiency decreases. Systems with bad usability cause errors and inefficiency.

Usability has many different forms of potential benefits also for the development organization. These benefits include increased productivity due to less user errors and less time spent on work tasks. An Information Technology application was introduced few years ago in hospitals in Finland for recording dictations by medical doctors as part of their routine practice after their appointment with a patient. However, the usability of this system was bad and for example saving one dictation required sixty (60) mouse clicks (National Audit Office of Finland 2012). So, if we assume that each selection took at least one second, just saving the dictation took one full minute extra time from the medical doctors that could had been used for patient appointments. One extra minute per patient may not sound like a too long time, but when we multiply this time with the target amount of patients per doctor in one day (12) we can see that each doctor was missing at least one patient meetings each day due to having to do unnecessary selections in a task that should had required only couple of clicks from the user interface. And if we want to calculate the worst-case scenario, when we multiply this wasted time with the total amount of medical doctors in Finland (21.000), we can do a rough estimation that cumulatively there may be as much as 525 working days $(1$ minute lost per patient $* 12$ patients per doctor per day $* 21.000$ doctors $=252.000$ minutes or 4200 hours or 525 working days) potentially lost every day because of just one usability issue in just one task performed using just one Information Technology application.

In addition to the traditional software development context, the emergence of online commerce has shifted the emphasis from the advantages of better usability to the penalties of the online commerce site not having good usability. But even today there are quite few product development organizations reportedly having incorporated usability activities fully in their product development process (Rajanen et al. 2017). Bringing usability activities into the commercial development life cycle has been a challenge since the beginning of the usability activities over fifty years ago (Rajanen \& Iivari 2007, Rajanen 2011). One reason for these difficulties is that the benefits of better usability are not easily identified or assessed. Usability activities have been competing for resources against other stakeholders in the SW development projects that do have objective and convincing cost-benefit data available for management decision making when the resources are allocated. Justifying the costs and identifying the benefits of the usability improvement activities have been seen as challenges for bringing usability activities into Information Technology Application development projects. Bringing usability into commercial software development is still a challenge. Furthermore, explicit introduction and justification of user centred design and usability work by managers is important in software development context, because software developers cling to status quo and seek to preserve it, by claiming that they follow the principles of user centred design and evaluation while in practice they do not, even if they desire to develop for high usability (Wale-Kolade \& Nielsen 2016). Usability work will be integrated in the organization and software development context when a strategic decision is made by the decision makers to incorporate it into the business and development processes of the organization (Venturi et al. 2006). According to Venturi et al. (2006), the usability work is fully integrated in the organization when it is included in the product lifecycle, the usability experts have access to required skills and expertise, there is organizational usability infrastructure in place, management is fully committed to usability work, usability and user centred culture is disseminated inside and outside of the organization, and results from usability work inform and impact the design decisions. 
In the early days of information technology, the SW developers were usually themselves the users of the SW they wrote and, therefore, knew their own needs and the context of use. Now IT solutions are used everywhere, and users can be of any age, from any culture, or from any context imaginable. The SW developers no longer have direct knowledge about the tasks, skills, and experience of the users, or information about the context within which the system is used. This can result in SW that does not answer to the functional needs of the user, but has plenty of extra unnecessary features, and does not sit well in the established work process of the user. SW developers need information about users and the context of use. User-centred design (UCD) has been developed to fulfill this role. According to international standard ISO 13407, user-centred design can be described as consisting of four principles and four iterative design activities. The four principles of user-centered design identified in ISO 13407 are:

- Active involvement of users in design activities

- Iterative design where design solutions are produced in iterative and incremental fashion

- Multi-disciplinary design where skills and views of people with various backgrounds are utilized in the design

- Allocation of tasks and functions to system and to user where appropriate

The four user-centered design activities need to start at the beginning of a development project in iterative fashion, and these activities identified in ISO 13407 are:

- Understanding and specifying the context of use

- Specifying the user, task, and organizational requirements

- Producing design solutions

- Evaluating designs against requirements

The iterative and incremental user-centered design process continues until the design solution is evaluated as fulfilling all the user and organizational requirements (ISO 13407).

The user-centered design process may include several usability actions to improve usability. In understanding and specifying the context of use and specifying the user and organizational requirements, these usability improvement actions can be, for example, creating personas, customer visits, and usability requirement workshops (c.f. Gulliksen et al. 2003). In producing design solutions and evaluating those against requirements, the usability improvement actions can be in the form of paper prototyping, expert evaluation, usability testing, and so on (Gulliksen et al. 2003).

One recent study has examined user-centeredness in the systems development context from the viewpoint of the four principles of user-centered design. This study found that there are considerable variations in how four allegedly user-centered systems design methods address the four principles of user-centeredness (Iivari \& Iivari 2010).

Furthermore, a user centred design justification survey illustrated that $62 \%$ of the respondents felt that user centred design was justified through individual testimonials of practitioners, case studies, as well as demonstrated potential results, while $23 \%$ of the respondents were convinced by support from customers, management, and outside companies, and only $15 \%$ of the respondents of the survey identified usability cost-benefit analysis as a method for justifying user centred design (Harrison et al. 1994). However, more than half of the informants believed that usability cost-benefit analysis for user centred design justification would have been more convincing for them if more details were provided on how the usability cost-benefit analysis model worked and what kind of assumptions and data were provided (Aydin \& Beruvides 2014; Harrison et al. 1994). Indeed, the usability cost-benefit analysis is one of the most important tools that is advocated in the literature by the researchers for justifying the costs of usability work, even though the usability researchers and practitioners do not have access or reference for reliable quantitative data for justifying usability work (Rajanen 2011). However, if quantitative approach for usability cost-benefit 
justification is used, it is extremely important to show to the decision makers that the data and the assumptions are reliable, or else there may be unforeseen consequences such as costs becoming more tangible than the benefits, and the focus shifting from the users to paying customers (Rajanen \& Iivari 2007).

\section{COST-BENEFIT ANALYSIS}

Cost-benefit analysis is a method for making a judgement about project or related actions from the investment point of view (Karat 1994). The cost-benefit analysis method is based on making investment decisions based on the comparison between estimated costs and benefits of the planned project or actions. The comparison between costs and benefits is based on collected and analyzed quantitative and qualitative data regarding technology and finance. This comparison allows the management to focus the limited resources that are available to the planned activities that have potentially low costs and potentially high benefits, bringing the company net benefit. While there are numerous cost-benefit models for different contexts ranging from restricting carnivorous plants (Givnish et al. 1984), rural to urban migration (Speare 1971), and to electronic medical records (Wang et al. 2003), there are surprisingly few published models for analyzing the costs and benefits of usability in the software development context. There is still a need for studies where usability cost-benefit analysis models have been employed in empirical settings, or where the results of using usability cost-benefit analysis in a case study would have been contrasted with the literature on usability cost-justification or usability cost-benefit analysis.

According to Burrill \& Ellsworth (1980) the general cost-benefit analysis method has three steps:

1. Identify the financial value of expected project cost and benefit variables.

2. Analyze the relationship between expected costs and benefits using simple or sophisticated selection techniques.

3. Make the investment decision.

Cost means the estimated monetary or abstract expense of doing an action, such as performing usability evaluation, or starting a project. This cost can be either easily measurable and quantifiable, or it can be abstract and, therefore, difficult quantify in financial terms (Burrill \& Ellsworth 1980). The objective of the cost-benefit analysis is to find more or less accurate financial estimates for each of the concrete and abstract. Sometimes it is not possible to estimate the financial impact of the abstract costs reliably. In that case, the best estimate or the range of various estimates should be used and the inaccuracy of the estimation should be taken into account.

In a software development project, the typical concrete and easily measurable costs are direct expenses (e.g., project personnel salaries and project office expenses), one-time purchases (e.g., equipment and software needed in development), one-time deployment costs (e.g., reduced individual and organizational productivity due to implementing new technology) and continuous overall expenses (e.g., training of the personnel). In addition to these easily measurable concrete costs, there many kinds of abstract costs. For example, the lack of knowledge transfer due to high staff turnover causes substantial indirect costs that are very difficult to estimate and quantify in monetary terms.

Benefit in cost-benefit analysis is a positive result of the planned action through either cost saving or estimated added value for the organization (Burrill \& Ellsworth 1980). Just like costs, benefits can be divided into concrete and abstract benefits. Typical concrete benefits in projects can be divided as improved productivity (e.g., due to less expenses or when limited resources are used more efficiently), improved effectiveness (e.g., by optimizing the provided services) and indirect benefits (e.g., using the analysis for 
process improvement) (DIRKS 2003). Abstract benefits that are difficult to quantify might be, for example, increase in customer loyalty or better reputation of the company.

\section{USABILITY COST-BENEFIT ANALYSIS}

Different metrics have been used to justify the costs of usability activities, such as Return on Investment on Usability and Total Cost of Ownership (Aydin et al 2011). However, these metrics include many subjective estimations on costs and benefits of usability improvements, and even at best the accuracy of these estimations depend largely on the experience of the usability practitioner and the quality of the data that is available for them (Aydin et al 2011, Rajanen 2011, Rajanen 2006). And without good data and good estimations, the cost-benefit analysis can be unreliable. Usually, the costs of usability can be estimated quite reliably, while the benefits of usability are far more difficult to identify, estimate and quantify, which may lead to the management focusing on the costs of usability and unintended consequences (Rajanen \& Iivari 2007, Rajanen 2011). Furthermore, there are few actual case studies reported in the literature that would show concrete data on the costs and benefits of usability improvements (Aydin et al 2011, Rajanen 2011), as the companies may be reluctant to reveal required financial and operational information to researchers. Furthermore, only one study addresses the comparison of the estimated and realized usability costs and benefits (Wilson \& Rosenbaum 2005), while realized usability benefits are usually brought up in blogs, private conversations, and workshops. Therefore, while it would be very interesting to conduct and report a usability cost-benefit analysis based on empirical data from a company, in practice companies either do not want to reveal such information or they want researchers to keep such information confidential. For example, it would be interesting to conduct a longitudinal study with usability cost-benefit analysis, spanning for example 5 years, but there has not been any reported cases or available empirical data. However, the literature still identifies the usability cost-benefit analysis as one of the key methods for practitioners to justify the costs of usability work. However, the reliability of the existing usability costbenefit analysis models may not be any more as good as it might have been over 15 years ago when these models were originally made. Information Technology applications have made great advancements in capabilities of technology and support of organizations and users. Furthermore, also the capabilities and the level of experience of the average users is much higher now than it was back then. At that time making an e-commerce web shop usability better might have given the company a substantial competitive advantage, whereas now the required level of usability is much higher in e-commerce and the companies cannot afford to launch web shops with poor usability. However, the usability experts in small, medium and large organizations still have the extremely important responsibility of convincing the organizational management and other decision makers to invest in usability work (Aydin \& Beruvides 2014).

There are surprisingly few published models for analyzing the benefits of usability in development organizations. This chapter presents usability cost-benefit analysis models that are both seminal and modern. The seminal models have been presented in the book Cost-Justifying Usability (Bias \& Mayhew 1994) are by Ehrlich and Rohn, Karat, and Mayhew and Mantei. The second edition of the book had a specific focus of applying usability cost-benefit considerations to web and intranet contexts, but it did not change the usability cost-benefit analysis models presented already in the first edition of the book (Bias \& Mayhew 2005). This book includes studies by various researchers in the field on usability cost benefit analysis. These studies are seminal, and they still continue to influence researchers and practitioners (Aydin et al. 2011, Rajanen 2011, Rajanen \& Rajanen 2017). In addition, the chapter explores usability cost-benefit analysis models by Bevan (2000) and Donahue (2001), as well as more modern models that relate to usability cost-benefit analysis in open source software development context (Rajanen 2011, Rajanen \& Iivari 2010), in games and gamification (Rajanen \& Rajanen 2017), and the most recent and radically different model (Aly \& Sturm 2019). These models are very different in their categorization, view and approach of the usability cost and benefits. Next, the usability cost-benefit analysis models and usability cost-justification models are presented. 


\section{Potential benefits through usability work}

Ehrlich and Rohn $(1994,2005)$ view the potential benefits of better usability through usability work and adoption of user-centred design from three points of view: vendor company, corporate customer and end user. According to them both the development company itself and the customers can gain benefits when usability activities are incorporated into software development project.

According to Ehrlich and Rohn the software development company can have three types of benefits:

1. Increased sales

2. Reduced support costs

3. Reduced development costs.

It may be difficult to estimate the impact of better usability and increased sales, but one way is to identify how important role does the usability has in buying decision (Rajanen 2006). One of the most prominent examples of the importance of usability to sales is by Spool (2008) in article "The $\$ 300$ million button". This article presents a rare case of quantified usability benefit analysis. In this case e-commerce site that had a simple interface as part of their online purchasing form: two fields, two buttons, and one link (Spool 2008). However, it turned out this part of the purchasing process was preventing customers, to the tune of $\$ 300,000,000$ a year. Furthermore, the designers of the site had no clue the web form had a problem that was costing the company huge amounts of money every year in lost sales.

The form itself was very simple, it had fields "Email Address" and "Password", buttons "Login" and "Register", and the link was "Forgot Password". The usability issue was not in the form elements or the layout itself, as much as it was the context where the form was presented to the users (Spool 2008). Users would be presented this form after they added products to their shopping cart and pressed the "Checkout" button. The problem was that the form came before the users could actually enter the information for payment and shipment for the product. The users were mentally prepared to finish the sale process and then the e-commerce site required them to either register or to remember login information from their past. As one shopper told the usability experts who were fixing the problem: "I'm not here to enter into a relationship. I just want to buy something" (Spool 2008). Other e-commerce sites offered a more streamlined shopping experience and good usability, and surprisingly large number of users abandoned their shopping process, the e-commerce company losing their sale. The usability issues were fixed, and the process was made streamlined. As a result of these usability improvements, the number of customers finalizing their purchases went up by $45 \%$. These extra purchases resulted in an extra $\$ 15$ million during the first month. For the first year, this e-commerce company saw increase of sales worth for an additional $\$ 300,000,000$ (Spool 2008).

The cost of providing product support for the customer companies and end users can be surprisingly high if there are usability problems in important product features and the product has lots of users who contact the customer support. Usability improvements have direct impact to the amount of product support needed and therefore less need for support due to better usability can lead to great savings (Rajanen 2002, Rajanen 2003, Rajanen \& Jokela 2004, Rajanen 2006). The customer organization can have potential benefits when a more usable product reduces time needed for the end user training. Furthermore, in addition of the official training, organizations have also hidden costs from unofficial peer-support. End users often seek advice from their colleagues, who spend their time helping rather than being productive. It is estimated that hidden support cost can be as high as $\$ 15.000$ per PC every year if the users are not experienced PC users (Bulkeley 1992).

End users are the final beneficiaries of a more usable product. According to Ehrlich and Rohn $(1994,2005)$ the better usability can bring benefits for end users through higher productivity, reduced learning time and 
greater work satisfaction. The users can benefit from higher productivity when the most frequent tasks take less time, such as in the earlier mentioned case of system for recording dictations by doctors.

\section{Benefits of usability work}

Bevan (2000) categorizes the potential benefits of usability work, user-centered design and better usability to the organizations during development, sales, use and support. The development organization can gain benefits in development, sales and support. Customer organization can benefit in use and support. When system is developed to be used in-house by the development organization it can gain benefits in development, use and support. In each of these categories, there are numerous possible individual benefits where either savings or increased revenue can be gained. The total amount of potential benefits from better usability can be estimated by adding all identified individual benefits together. Bevan identifies usability benefits from increased sales, less need for training and increased productivity. Benefits from decreased development time are identified but not discussed in detail.

\section{Quantifying human factors work}

Karat $(1994,2005)$ approaches the usability benefits through evaluating and quantifying the human factors work. This viewpoint differs from other usability benefit models in the literature. Karat identifies some examples of potential benefits in three categories:

1. Increased sales

2. Increased user productivity

3. Decreased personnel cost through smaller staff turnover

The development organization can expect benefits through better usability giving them a competitive edge and therefore increased market share and sales. Customer organization can gain benefits through increased end user productivity when task times are reduced and further indirectly when better usability increases staff satisfaction and reduces staff turnover. Karat has three phases in usability cost-benefit analysis. In the first phase all expected usability costs and benefits are identified and quantified. In the second phase the costs and benefits are categorized as being either tangible or intangible. The intangible costs and benefits are moved into separate list, as they are not easily estimated and quantified. The third phase is to determine financial value for all the tangible costs and benefits, but not to the intangible costs and benefits. Karat also highlights the importance of business cases in the usability cost-benefit analysis, as the business cases can provide an objective and debatable basis for making decisions on organizational investments such as usability work (Karat 1994).

\section{Identifying benefit categories}

Mayhew and Mantei $(1994,2005)$ view what the cost-benefit analysis of usability work is best made by focusing the attention of the audience, such as the managers, on the benefits that are of most interest to them. The benefit categories which are relevant for this particular target audience are then identified and the potential benefits are identified, estimated and calculated. Examples of relevant benefit categories are given for development company and developing in-house system for the development organization:

1. Increased sales

2. Decreased customer support

3. Making fewer changes in late design life cycle

4. Reduced cost of providing training. 
The benefits for in-house development can be gained from increased user productivity due to better usability resulting less mistakes, decreased number of user errors, decreased training costs, having to make fewer changes in late design life cycle and the less need for user support. To estimate each of these possible benefits, a unit of measurement is chosen. Then an estimation is made concerning the magnitude of the benefit for each unit of measurement. The estimated benefits per unit are then multiplied by the number of units.

\section{Cost-Justifying Usability through fear-setting}

Aly and Sturm (2019) have a completely different approach to usability cost-benefit analysis and justification of usability work. They argue that the usability, user experience and user-centered design professionals are in essence running negotiations with product owners about cost justification of usability activities, and that a different approach from traditional usability cost-justification or "goal-setting" is needed for convincing the managers and decision-makers to invest in usability work. They suggest a new approach, namely "fear-setting", which highlights the importance of avoiding losses resulted from bad usability and the related costs and losses in sales that originate from not taking any action related to usability improvement (Aly \& Sturm 2019). The cost of inaction is defined as the opportunity cost which is associated with organizations not deploying the necessary technological or business improvements to match the complexity of their business (Hagan 2017). This radical change of approach from promising benefits to avoiding losses originates from the need that the usability experts must communicate the value of usability across multiple levels in organization and that is why several "languages" are needed to communicate in different levels (Bloom et al. 1997). So instead of speaking about need for usability work in defensive mode and trying to argue that eventually the benefits will be greater than initial costs, the usability professionals should consider their audience and language appropriately, and in case of management the "fear-setting" language might be more effective, focusing on potential losses if no usability work is done, instead of focusing on cost-justification (Aly \& Sturm 2019). They argue that presenting losses that might result from inaction, might have more influence on management decision, than notions of potential profits gained from an action, as the fear of loss is the most undesirable feeling a business owner or manager can feel, and therefore addressing the missed opportunities due to bad usability, costs and losses resulted from indecision about investing to usability work can work as intimidating stimuli, and then there is no need to justify the usability costs any further (Aly \& Sturm 2019). Their results give a first direction for future studies, for example taking into account the age of the audience: the younger and less experienced managers might consider potential profit and be better targets for traditional usability cost-benefit analysis, while the older and more experienced managers consider more losses and cost of inaction (Aly \& Sturm 2019). However, this approach and its psychological aspects have not been yet tested empirically.

\section{Dangers of traditional usability cost-benefit analysis}

Rajanen \& Iivari (2007) examined in their case study the process of meanings negotiation related to usability and its cost-benefit analysis in Information Technology application development organization. Existing literature shows that very divergent meanings can be attached to usability in practice, as there are studies showing that usability as a concept has been used only as a slogan, or buzzword without any proper understanding of it (Rajanen \& Iivari, 2007). In their case study Rajanen \& Iivari (2007) identified that the case organization used the potential usability benefit of increased sales as a tool in sales and marketing, as a tool for convincing the customer, resulting in marketing demos that sell themselves and conquer the world, while not actually conducting much usability work (Rajanen \& Iivari 2007). In the eyes of the management, the reduced development costs through usability meant that the customers should be kept out of the development by any means. Furthermore, the costs of usability work, such as user interface design and development costs that would have been realized in any case even if no usability work was done, resulted the management condemning the usability activities as ineffective and time consuming. In the eyes of these managers, the benefits of better usability remained too distant and difficult to estimate (Rajanen \& Iivari 2007). 
It can be argued that as the result of the introduction of usability cost-benefit analysis as a concept, the costs of usability were made to appear very clearly, while the possible usability benefits remained too vague to really make an impact to the attitude of the managers (Rajanen \& Iivari 2007). The benefits of better usability were not given any time to become visible, as the managers decided to halt the usability improvement efforts so quickly. The promises of future usability benefits were clearly not enough for the management to continue the usability activities. The traditional usability cost-benefit models assume that the usability benefits could and should be quantifiable and comparable. However, these assumptions are problematic because many of the usability benefits identified in the traditional usability cost-benefit analysis models are intangible and speculative by nature and trying to quantify them without any evidence only seems to raise suspicions (Rajanen \& Iivari, 2007). Therefore, it can be argued that the usability benefits should only be quantified when there is both an empirically tested formula for calculating the usability benefits and also reliable data to be inputted into that formula (Rajanen \& Iivari 2007).

In addition, some of the possible benefits of better usability that the traditional usability cost-benefit models identify were considered as insignificant by the managers. For example, having to print fewer pages for the product manual was raised as a possible benefit through better usability by many traditional usability costbenefit analysis models, but the managers in the case organization even discussing this benefit just a waste of time. In their view the impact of this benefit was insignificant in first place, and furthermore the identified benefit did not take into account the transition from printed manuals to digital and online manuals. This example shows that the traditional usability cost-benefit analysis models are in great need of modernization and therefore they should be used only with great care (Rajanen \& Iivari 2007, Rajanen 2011).

\section{Usability benefits in games and gamification}

Computer games, online gaming and mobile gaming, as well as different forms of gamification have rapidly entered into our everyday life. Game development industry has boomed since the last decade. And since the last twenty years the game development has changed a lot in both scope and player requirements (Blow 2004). Game development covers a wide spectrum of developers ranging from an individual hobbyist creating a simple game to a large-scale AAA game development project costing hundreds of millions and having hundreds of development staff. The global sales of the game industry has already surpassed 100 billion US dollars (Newzoo 2016). The large gaming market has also become extremely competitive, and it has been estimated that just one out of five games reaching the markets make profit. Therefore, this one profitable game must pay not only its own development costs but also the development of the other less successful four games.

Because of competitiveness of the market and the increased demands of the gamers, bad game usability can cause monumental financial and reputation losses. Unlike many other forms of Information Technology applications, playing games is a voluntary activity and the players can freely choose which games they invest their money on (Rajanen \& Marghescu 2006). Furthermore, the gamers, game critics and game communities are very vocal about all problems. Therefore, critical reviews and views of bad usability reach far and fast and can seriously impact the success of the game (Rajanen \& Marghescu 2006).

One of the most prominent examples of the impact of bad usability was the original version of the Final Fantasy XIV, an online multiplayer MMORPG which had a catastrophic first launch in 2010. Being part of very popular game series, the launch was eagerly anticipated by large number of players and the expectations were high. However, the released game had numerous very severe user interface and usability problems, starting from the convoluted process for opening an account to play the game. When entering the game, the players were not sure what to do and where to go, as the game map did not label any important locations, did not allow zooming out and players had to use non-standard keyboard controls to scroll it. Furthermore, the user interface of the game was very unintuitive, slow, cumbersome and convoluted for PC 
gameplay, because it was designed for a console version, which did not even exist at the time of the launch. Additionally, the user interface did not follow the established best practices and standards of the MMORPG genre. As one game reviewer put it bluntly: "These and countless other oddities make interacting with Final Fantasy XIV a chore" (GameSpot 2010). These kinds of negative professional and amateur reviews, forum posts and word-of-mouth were disastrous for the sales. Because of these usability problems and in response to heavy criticism and massive losses in the numbers of paying players, the publisher Square Enix abandoned the original version of the game and sacked its development team. Completely new version of the game was released in 2013, and in this version the usability problems were fixed.

Rajanen \& Rajanen (2017) address the benefits of better usability in the development of games and gamification. Gamification is defined as using game-like elements in non-gaming context, usually for motivating and engaging the user to act in a certain way, such as to learn something or to change their behavior in some way (Deterding et al. 2011). Rajanen \& Rajanen (2017) categorize the benefits of better usability in two categories: usability benefits in gamification development and usability benefits in gamification use.

In the context of developing a game or gamified system, better usability can contribute to 1) increased sales as the business objectives are well defined, understood and embedded in the game, 2) reduced development costs due to iterative design and development making sure that the critical issues of target behaviours, players profiles, activity loops for player engagement and motivation, fun of the game, and deployment solutions are well tested before implementation, thus resulting in less need for later costly changes, 3) reduced training and support costs as the game is tailored and adapted to the players and not vice versa, and by understanding, knowing and modelling the target players for the optimal effect, and 4) increased acceptance and reputation since the potential customers and end-users are adopting the game and provide positive feedback though different channels.

In the context of using a game or gamified system, better usability can contribute to 1) increased productivity as the game design is based on the business objectives and ensuring the usability, UX, flow and fun, as well as engagement and achieving the target behaviour, 2) reduced errors as the game is designed according to usability requirements for ease of use, effectiveness, and efficiency, as well as UX requirements of subjective experience with respect to the target behaviour and business objectives, 3) reduced training time and learning effort when the activity loops for progression and engagement are designed by continuously involving the users, and 4) increased customer and user satisfaction as the potential customers and end-users are adopting the game and provide positive feedback through different channels.

\section{Usability benefits in open source software development context}

Open source software development means development of software where the source code is made freely available for everyone to read and modify (Rajanen \& Iivari 2010). The fundamental philosophy is to enable software to evolve by exploiting voluntary community participation (Rajanen 2011). Open source software development makes it possible also for the end-users to adapt the software they use to their personal needs and to fix defects. Since the last decade, also Information Technology companies have started to use open source software development in their business. Using open source software applications and development tools has been common for a long time, but also using the actual source code as part of software development has become popular. The availability of free, ready-made components updated by volunteer developers can reduce the development costs substantially. Additionally, software development companies have also started to participate in OSS communities and even to launch new open source projects. Therefore, introducing and incorporating usability work into open source software development context is important (Rajanen 2011). However, introduction of usability into open source software development has been a challenge for a long time (cf. Rajanen \& Iivari 2010). 
Rajanen \& Iivari (2010) and Rajanen (2011) introduced usability cost-benefit analysis model for open source software development context. Their model categorizes the benefits of better usability into two categories: community open source software development context and company open source software development context.

In the traditional community open source software development context the better usability can 1) increase the popularity and distribution of that particular open source software, 2) attract an increased number of active and committed developer-users and non-developer -users, 3) increase the developer-user and nondeveloper-user satisfaction, 4) put less pressure for redesign through change requests in the forums, 5) having more systematic redesign, and 5) less need for peer support in the forums

In the company open source software development context, where a commercial software development company is involved in open source software development, better usability can benefits through 1) increased number of active and committed developer-users and non-developer -users, and some of them are also willing to become paying customers, 2) increased developer-user and non-developer-user satisfaction, 3) reduced development costs, 4) less pressure for changes presented in the forums, 4) more systematic redesign, 5) reduced training and support costs, and 6) if company provides training and support, less need for them

\section{CONCLUSION}

The aim of this chapter was to give a 1) comprehensive overview as well as 2) example cases of the importance of good usability and user experience (UX) for the development organizations, customer organizations and end users, as well as providing 3) practical tools for the management for making strategic business cases for better usability and UX, and introducing usability and UX activities into the development process.

Therefore, this chapter contributes to the usability cost-benefit analysis research in three ways. First, there is still a considerable lack of studies on different usability cost-benefit analysis models. This chapter identified the main strengths, weaknesses, commonalities and differences between usability cost-benefit analysis models. There are considerable differences between models in the usability cost-benefit analysis literature, in identifying and documenting the individual usability costs and benefits, and the necessary steps of the outlined cost-benefit analysis in general, as well as the theoretical soundness. These existing usability cost-benefit analysis models should be further updated to match the needs of the new era of ubiquitous and mobile Information Technology applications. These results are in line with the research which has pointed out a declining trend in primary theory development in usability cost-benefit analysis research and usability cost justification research (Aydin et al., 2011). Therefore, this chapter repeats this call for action for the researchers to do further primary theory development on this field and to test their theoretical frameworks empirically.

Second, this research contributed to the theoretical and practical usability cost-benefit analysis by highlighting the risks of applying the usability cost-benefit analysis or usability cost justification without great care, as there are risks that the intended purpose of using the usability cost-benefit analysis as motivation for usability work is jeopardized because the inherent costs of better usability become too apparent. This chapter identifies a reported empirical case where usability cost-benefit analysis raised new and unexpected issues. Therefore, this chapter can be useful for usability cost-benefit

Third, this chapter explored applying the usability costs and benefits into new contexts to fit them in important Information Technology development contexts: open source software development context and game and gamification development context. The results indicate that it is possible to fit the usability cost- 
benefit consideration into these new contexts, and that similar usability cost-benefit analysis models and usability cost-justification models should be created for similarly important Information Technology application development contexts, such as ubiquitous technologies, Virtual Reality, Augmented Reality, Mixed Reality, and the $5 \mathrm{G}$ and $6 \mathrm{G}$ networks, to name just a few potential areas for future studies.

Fourth, this chapter can help the usability practitioners in development organizations to find the best arguments for investing to usability work and better usability, and to convince the management that investing on better usability is not just economically smart, but that it can be also vital for the very survival of the organization.

Future research should be aimed for developing new and up-to-date cost-benefit analysis aspects, techniques and models with strong theoretical and empirical backgrounds, that are suitable for researchers and practitioners in private and public sectors.

\section{REFERENCES}

Aly, M., \& Sturm, C. (2019). Hacks for Cost-Justifying Usability: Fear-Setting vs. Goal-Setting. In Proceedings of the 21st International Conference on Human-Computer Interaction with Mobile Devices and Services (p. 77). ACM.

Aydin, B., Millet, B., \& Beruvides, M. G. (2011). The State-Of-The-Art Matrix Analysis for Cost-Justification of Usability Research. Proceedings of the American Society for Engineering Management: Winds of Change, Staking paths to explore new horizons, Lubbock, Texas, 221229.

Bloomer, S., Croft, R., \& Kieboom, H. (1997). Strategic usability: introducing usability into organisations. In CHI'97 Extended Abstracts on Human Factors in Computing Systems (pp. 156157). ACM.

Blow, J. (2004). Game development: Harder than you think. ACM, 1(10), pp. 28-37.

Deterding, S., Sicart, M., Nacke, L., O'Hara, K., \& Dixon, D. (2011). Gamification: using gamedesign elements in non-gaming contexts. In CHI'11 Extended Abstracts on Human Factors in Computing Systems (2425-2428). ACM.

Hagan, J. (2017). The Cost of Status Quo: When is it Time to Look at a Software Change?. Managing Partner of One Motion Technologies Inc. Retrieved from https://www.linkedin.com/pulse/cost-status-quo-when-time-look-software-change-josh-hagan

Harrison, M. C., Henneman, R. L., \& Blatt, L. A. (1994). Design of a human factors costjustification tool. In Cost-justifying usability (pp. 203-241). Academic Press, Inc.

Iivari J. \& Iivari N. (2010). Varieties of user-centredness: an analysis of four systems development methods. Information Systems Journal. 21(2): 125-153

ISO 9126. (1991). ISO/IEC 9126 Information technology-Software Product Evaluation-Quality characteristics and guidelines for their use. International Standard. 
ISO 13407. (1999). ISO/IEC 13407, Human-Centred Design Processes for Interactive Systems, International Standard.

ISO 9241-11. (1998). ISO/IEC. 9241-14 Ergonomic requirements for office work with visual display terminals $(V D T) s$, International Standard

Marghescu, D. (2009). Usability evaluation of information systems: A review of five international standards. In Information Systems Development (pp. 131-142). Springer, Boston, MA.

National Audit Office of Finland. (2012). Käyttäjäystävällisillä tietojärjestelmillä jopa 400000 lääkärin vastaanottoaikaa lisää. Retrieved from: https://www.vtv.fi/tiedotteet/kayttajaystavallisillatietojarjestelmilla-jopa-400-000-laakarin-vastaanottoaikaa-lisaa/

Newzoo. (2016). Global Games Market Report. Q2 2016 Update.

Nielsen, J. (1993). Usability engineering. Boston: Academic Press

Rajanen, D., Clemmensen, T., Iivari, N., Inal, Y., Rızvanoğlu, K., Sivaji, A., \& Roche, A. (2017). UX professionals' definitions of usability and UX-A comparison between Turkey, Finland, Denmark, France and Malaysia. In IFIP Conference on Human-Computer Interaction (pp. 218-239). Springer, Cham.

Rajanen, M. \& Rajanen, D. (2017). Usability Benefits in Gamification. Proceedings of the 1st GamiFIN Conference, Pori, Finland.

Rajanen, M. (2011). Applying Usability Cost-Benefit Analysis - Explorations in Commercial and Open Source Software Development Contexts. PhD Dissertation. Acta Universitatis Ouluensis Series A 587. University of Oulu.

Rajanen, M., \& Iivari, N. (2015). Examining usability work and culture in OSS. In IFIP International Conference on Open Source Systems (pp. 58-67). Springer, Cham.

Rajanen, M., Iivari, N. (2010). Traditional Usability Costs and Benefits - Fitting them into Open Source Software Development. In proceedings of the 18th European Conference on Information Systems (ECIS 2010).

Rajanen, M., Iivari, N. (2007). Usability Cost-Benefit Analysis: How Usability Became a Curse Word?. In Proceedings of the INTERACT 2007. Rio de Janeiro, Brasil.

Rajanen, M. (2007). Usability Cost-Benefit Models - Different approaches to Usability Cost Analysis. In Proceedings of the 9th International Conference on Enterprise Information Systems (ICEIS 2007). Funchal, Madeira, Portugal.

Rajanen, M. (2006). Different Approaches to Usability Cost-Benefit Analysis. In proceedings of 13th European Conference on Information Technology Evaluation (ECITE 2006), Genoa, Italy. 
Rajanen, M., Marghescu, D. (2006). The Impact of Game Usability to Player Attitude. In proceedings of 29th Information Systems Research Seminar In Scandinavia (IRIS29), Helsingoer, Denmark.

Rajanen, M., Jokela, T. (2004). Analysis of Usability Cost-Benefit Models. In proceedings of the 12th European Conference on Information Systems (ECIS2004), Turku, Finland.

Rajanen, M. (2003). Usability Cost-Benefit Models - Different Approaches to Usability Benefit Analysis. In proceedings of 26th Information Systems Research Seminar In Scandinavia (IRIS26), Haikko, Finland

Rajanen, M. (2002). Assessing the Business Benefits of Usability in the Product Development Project - Analysing the Existing Models. In proceedings of 25th Information Systems Research Seminar In Scandinavia (IRIS25), Bautahoej, Denmark

Raskin, J. (2001). The humane interface: new directions for designing interactive systems. Addison-Wesley Professional.

Schneiderman, B. (1998). Designing the User Interface: Strategies for Effective HumanComputer Interaction. 3rd ed. Reading: Addison-Wesley

Spool, J. (2008). The $\$ 300$ million button. In: Wroblewski, Luke. Web form design: filling in the blanks. Rosenfeld Media, 2008.

Venturi, G., Troost, J., \& Jokela, T. (2006). People, organizations, and processes: An inquiry into the adoption of user-centred design in industry. International Journal of Human-Computer Interaction, 21(2), 219-238.

Wale-Kolade, A., \& Nielsen, P. A. (2016). Apathy towards the integration of usability work: a case of system justification. Interacting with Computers, 28(4), 437-450. 


\section{KEY TERMS AND DEFINITIONS}

Cost-Benefit Analysis: Making an investment decision based on the estimated costs and benefits of the planned activity

Usability: The extent to which an Information Technology application, product, software, system or service can be used easily, can be used without errors and can be learned easily by the users.

Usability cost-benefit analysis: Comparing the costs and benefits of usability improvement activities in order to motivate investing to usability improvement

Usability cost justification: Motivating investing to usability improvements by showing that benefits of better usability are greater than costs.

Usability improvement: Measurable improvement in usability of an Information Technology application, product, software, system or service, when compared to previous version or to competitors

Usability work: Planning, design and testing activity, which aims to improving usability of an Information Technology application, product, software, system or service

User-centered design: Iterative and incremental process for designing and developing systems with good usability

User experience: Experience of an individual user in terms of ease and pleasantness of the use of an Information Technology application, system or service. 